frequent impairment on work (66\%) and personal life (87\%) and the highest use of analgesics (60\% NSAIDs, $25 \%$ opioids and $40 \%$ others). In the regression analyses, BMI per 5 units and WHO-5 per 10\% worsening were associated with an increase in WOMAC values of 3-4 points, irrespective of the joint manifestations.

\begin{tabular}{|c|c|c|c|c|c|c|}
\hline & & & \multicolumn{4}{|c|}{ WOMAC } \\
\hline & Parameter & Reference & Polyarthrosis & Hip OA & Knee and Hip OA & Knee OA \\
\hline \multirow[t]{2}{*}{ Model 1} & Age & per 10 years & $0,7(-0,6 ; 2,0)$ & $0,7(-1,2 ; 2,6)$ & $2,0(-0,5 ; 4,4)$ & $-0,1(-3,5 ; 3,3)$ \\
\hline & Gender: Male & Female & $-3,8(-6,7 ;-1,0)$ & $0,8(-3,5 ; 5,0)$ & $-3,7(-8,1 ; 0,6)$ & $-0,5(-7,6 ; 6,6)$ \\
\hline tel $2^{*}$ & $\mathrm{BMI}, \mathrm{kg} / \mathrm{m}^{2}$ & per 5 units & $4,4(3,2 ; 5,5)$ & $3,1(1,1 ; 5,2)$ & $4,2(1,8 ; 6,6)$ & $4,1(0,6 ; 7,6)$ \\
\hline del $3^{*}$ & Symptom duratio & per year & $0,3(0,2 ; 0,5)$ & $0,4(0,2 ; 0,6)$ & $0,2(-0,0 ; 0,4)$ & $0,4(0,0 ; 0,8)$ \\
\hline el $4^{*}$ & w & 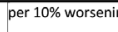 & $4.4(3.8 ; 5.0)$ & $3.2(2.2 ; 4.1)$ & $4.1(3.3 ; 5.1)$ & $3.9(2.1 ; 5.9)$ \\
\hline
\end{tabular}

Table: Results of four separate multiple linear regression models with the WOMAC as the dependent variable Regression coefficients with $95 \%$ confidence intervals are shown.

*Model adjusted for age, gender. BMI: Body Mass Index, OA: Osteoarthritis, WOMAC: Western Ontario and McMaster Universities Osteoarthritis Score.

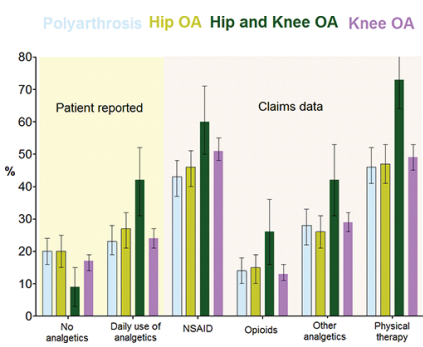

Abstract THU0429 - Figure 1. Patient reported use and claims data prescriptions of analgesics and physical therapy. NSAID: Non-steroidal anti-rheumatic drugs, OA: Osteoarthritis.

Conclusion: Disease burden is high in persons with concomitant knee and hip $\mathrm{OA}$, going along with frequent prescription of analgesics. The pattern of joint affection, BMI and depressive symptoms need to be considered when using the WOMAC as an outcome instrument.

Acknowledgement: This study was funded by the German Federal Ministry of Education and Research (01EC1405).

Disclosure of Interests: Johanna Callhoff: None declared, Katinka Albrecht: None declared, Imke Redeker: None declared, Toni Lange: None declared, Jens Goronzy: None declared, Klaus-Peter Günther: None declared, Angela Zink Speakers bureau: Speakers fees from AbbVie, Janssen, Pfizer, Roche, Sanofi, Jochen Schmitt: None declared, Anne Postler: None declared

DOI: 10.1136/annrheumdis-2019-eular.1202

\section{THU0430 PREPARING AN ORTHOPAEDIC CONSULTATION USING AN EHEALTH TOOL: A RANDOMIZED CONTROLLED TRIAL IN PATIENTS WITH HIP AND KNEE OSTEOARTHRITIS}

Aniek Claassen ${ }^{1}$, Henk J Schers ${ }^{2}$, Vincent Jjf Busch ${ }^{3}$, Petra Heesterbeek ${ }^{4}$, Frank van den Hoogen ${ }^{1,5}$, Thea Vliet Vlieland ${ }^{6}$, Cornelia van den Ende ${ }^{1,5} .{ }^{1}$ Sint Maartenskliniek, Department of Rheumatology, Nijmegen, Netherlands; ${ }^{2}$ Radboud University Medical Center, Department of Primary and Community Care, Nijmegen, Netherlands; ${ }^{3}$ Sint Maartenskliniek, Department of Orthopaedic Surgery, Nijmegen, Netherlands; ${ }^{4}$ Sint Maartenskliniek, Sint Maartenskliniek Research, Nijmegen, Netherlands; ${ }^{5}$ Radboud University Medical Center, Department of Rheumatology, Nijmegen, Netherlands; ${ }^{6}$ Leiden University Medical Center (LUMC), Department of Orthopaedics, Rehabilitation and Physical Therapy, Leiden, Netherlands

Background: Hip and knee OA patients who are referred to an orthopaedic surgeon often expect action to be taken. ${ }^{1}$ However, the majority who of those patients is not (yet) eligible for a joint replacement., ${ }^{2,3} \mathrm{We}$ hypothesized that a solid preparation using the eHealth tool is likely to streamline patients' expectations and increase satisfaction, irrespective of the outcome of the consultation.

Objectives: To evaluate the effect of a stand-alone mobile and webbased educational intervention (eHealth tool) compared to usual preparation of a first orthopaedic consultation of patients with hip or knee osteoarthritis (OA) on patients' satisfaction.

Methods: A two-armed unblinded randomized controlled trial involving 286 patients with (suspicion of) hip or knee OA, randomly allocated to either receiving an educational eHealth tool to prepare their upcoming consultation $(n=144)$ or usual care $(n=142)$. Satisfaction with the consultation on three subscales (range 1-4) of the Consumer Quality Index (CQI - primary outcome) and knowledge (assessed using 22 statements on $\mathrm{OA}$, range 0-22), treatment beliefs (assessed by the Treatment beliefs in OsteoArthritis questionnaire, range 1-5), pain medication use (yes/no), assessment of patient's involvement in consultation by the surgeon (assessed on a 5-point Likert scale) and patient satisfaction with the outcome of the consultation (numeric rating scale), were assessed.

Results: No differences between groups were observed on the 3 subscales of the CQI (group difference $(95 \% \mathrm{Cl})$ : communication 0.009 ($0.10,0.12)$, conduct $-0.02(-0.12,0.07)$ and information provision $0.02(-$ $0.18,0.21)$ ). Between group differences $(95 \% \mathrm{Cl})$ were in favour of the intervention group for knowledge $(1.4(0.6,2.2))$, negative beliefs regarding physical activities $(-0.19(-0.37,-0.002)$ and pain medication $(-0.30$ ($0.49,-0.01)$ ). We found no differences on other secondary outcomes. Conclusion: An educational eHealth tool to prepare a first orthopaedic consultation for hip or knee OA does not result in higher patient satisfaction with the consultation, but it does influence cognitions about osteoarthritis.

\section{REFERENCES:}

[1] Samsson KS, Bernhardsson S, Larsson ME. "Take me seriously and do something!" - a qualitative study exploring patients' perceptions and expectations of an upcoming orthopaedic consultation. BMC Musculoskelet Disord 2017 Aug 24;18(1):367

[2] Barten DJ, Smink A, Swinkels IC, Veenhof C, Schers HJ, Vliet Vlieland TP, et al. Factors Associated With Referral to Secondary Care in Patients With Osteoarthritis of the Hip or Knee After Implementation of a SteppedCare Strategy. Arthritis Care Res (Hoboken) 2017 Feb;69(2):216-25

[3] McHugh GA, Campbell M, Luker KA. GP referral of patients with osteoarthritis for consideration of total joint replacement: a longitudinal study. $\mathrm{Br} J$ Gen Pract 2011 Aug;61(589):e459-e468

Disclosure of Interests: None declared DOI: 10.1136/annrheumdis-2019-eular.2665

\section{THU0431 FREQUENCY OF TENDON INVOLVEMENT AND ITS EFFECT ON HAND FUNCTION IN HAND OSTEOARTHRITIS}

|rina Gess| ${ }^{1}$, Anna Vinatzer ${ }^{1}$, Gabriela Supp ${ }^{2}$, Michael Zauner ${ }^{1}$,

Michaela Loiskandl ${ }^{2}$, Martina Durechova ${ }^{1}$, Valentin Ritschl ${ }^{3}$, Josef S. Smolen ${ }^{1}$, Daniel Aletaha ${ }^{1}$, Peter Mandl' ${ }^{1}{ }^{1}$ Medical University of Vienna, Department of Medicine III, Division of Rheumatology, Vienna, Austria; ${ }^{1}$ Medical University of Vienna, Department of Medicine III, Division of Rheumatology, Vienna, Austria: ${ }^{3}$ Medical University of Vienna, Section for Outcomes Research, Vienna, Austria

Background: Tenosynovitis and consequent tendon damage are common findings in inflammatory arthritides. In contrast to rheumatoid arthritis (RA) and psoriatic arthritis, little is known about the frequency of tendon involvement in hand osteoarthritis ( $\mathrm{HOA})$ and the influence thereof on hand function. Ultrasound has been reported to have a high specificity in diagnosing tenosynovitis and tendon damage.

Objectives: We aimed to appraise the frequency of tendon involvement in HOA and to assess the agreement between ultrasound (US) and clinical diagnosis of tenosynovitis and tendon damage in HOA. In addition, we wanted to assess the influence of tendon involvement on hand function.

Methods: We included 73 patients with HOA in the study. Each patient underwent a clinical as well as a US examination of the 6 extensor tendon compartments and 6 flexor tendons of the hand (fig. 1). They were assessed for US signs of tenosynovitis and tendon damage as well as osteophytes (presence/absence) by a sonographer blinded to clinical information, as well as for clinical tendon involvement (presence/absence) by a biometrician blinded to the US results. Difference in frequency of sonographically detected tendon involvement between flexor and extensor tendons and between right and left hand were calculated by Chi-Square test. Osteophytes were also evaluated on standard radiographs. Agreement between US and clinical examination was calculated by Cohen's kappa. Hand function was quantified using the Score for the Assessment and Quantification of Chronic Rheumatoid Affections of the Hands (SACRAH) questionnaire as well as the Moberg pick-up test (MPUT). Correlation between MSACRAH and tendon involvement was calculated by Spearman's correlation.

Results: In 41 patients (56.2\%), at least one tenosynovitis was observed and in $8(11 \%)$ patients, at least one tendon damage was detected by US. Tendon damage was found more often in flexor tendons $(0.2 \%$ vs. $2.2 \%, p<0001$ ), while tenosynovitis was found more often in extensor 
tendons $(6.9 \%$ vs. $0.7 \%, p<0001)$. The right hand was affected more often by tendon damage than the left hand $(2.5 \%$ vs. $1.1 \%, \mathrm{p}<0.05)$, but not by tenosynovitis $(3.5 \%$ vs. $4 \%, p=0.7)$. Among all tendons, tenosynovitis affected most often the sixth extensor compartment (in 28.1\%), while tendon damage most frequently involved Flexor digitorum II and II (each $4.8 \%$ ) detected by US (fig. 1).

Clinically, any tendon involvement was observed in 57 (78.1\%) patients. There was no agreement between the US and the clinical examination on the level of individual tendons (kappa -0.0007) and only slight agreement on the level of individual patients (any affected tendon yes $/ \mathrm{no}$ ) (kappa 0.16). We also found no association between osteophytes (radiographic or US) and tendon involvement regardless of assessment. Neither total MSACRAH nor the MPUT correlated with the number of affected tendons detected by US. However, there was a slightly significant correlation between the number of clinically affected tendons and the MSACRAH subtest for hand function and stiffness.

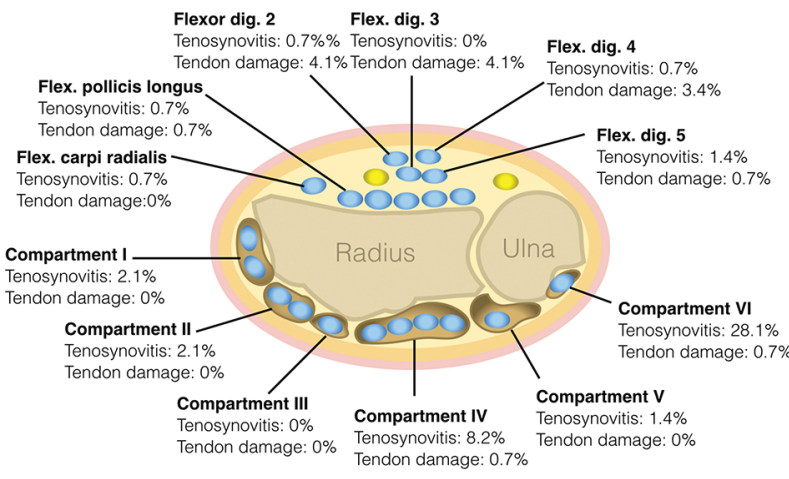

Fig.1 Distribution of tenosynovitis and tendon damage in the sonographic examination

Abstract THU0431 - Figure 1

Conclusion: This study revealed a high frequency of tendon involvement in HOA. The prevalence of tenosynovitis was similar as reported for RA and other inflammatory arthritides. The fact that we could demonstrate marked differences in the distribution of tenosynovitis and tendon damage between and among flexor and extensor tendons as assessed on US, coupled with the overall homogeneous clinical involvement, suggests that clinical examination may be less specific for tendon involvement as compared to US. Tendon involvement on US does not seem to have an impact on hand function in HOA.

Disclosure of Interests: Irina Gessl Grant/research support from: Travel Grant, Anna Vinatzer: None declared, Gabriela Supp: None declared, Michael Zauner: None declared, Michaela Loiskandl: None declared, Martina Durechova: None declared, Valentin Ritschl: None declared, Josef S. Smolen Grant/research support from: AbbVie, Eli Lilly, Janssen, MSD, Pfizer, Roche, Consultant for: AbbVie, Amgen, Astra-Zeneca, Astro, Celgene Corporation, Celtrion, Eli Lilly, Glaxo, ILTOO, Janssen, Medlmmune, MSD, Novartis, Pfizer, Roche, Samsun, Sanofi, UDB, Speakers bureau: AbbVie, Amgen, Astra-Zeneca, Astro, Celgene Corporation, Celtrion, Eli Lilly, Glaxo, ILTOO, Janssen, Medlmmune, MSD, Novartis, Pfizer, Roche, Samsun, Sanofi, UDB, Daniel Aletaha Grant/research support from: AbbVie, Bristol-Myers Squibb, and MSD, Consultant for: AbbVie, Bristol-Myers Squibb, Eli Lilly, Janssen, Medac, Merck, MSD, Pfizer Inc, Roche, and UCB, Speakers bureau: AbbVie, Bristol-Myers Squibb, Eli Lilly, Janssen, Medac, Merck, MSD, Pfizer Inc, Roche, and UCB, Peter Mandl: None declared

DOI: 10.1136/annrheumdis-2019-eular.7736

\section{THU0432 \\ LUMBAR FACET JOINT OSTEOARTHRITIS IS A RISK}

Zhi-xiang Huang ${ }^{1}$, LI Guo-Chao ${ }^{2}$, Qi MI ${ }^{2}$, Shi-Yu Wang ${ }^{2}$, Wei-Ming Deng ${ }^{1}$, LI TianWang'. ' Guangdong Second Provincial General Hospital, Department of Rheumatology and Immunology, Guangzhou, China; ${ }^{2}$ Ganzi Tibetan Autonomous Prefecture People's Hospital, Department of Rheumatology and Immunology, Ganzi Tibetan Autonomous Prefecture, China

Background: Degeneration of sacroiliac joints $(\mathrm{SIJ})$ is common in the general population, which associates with age, gender and body mass index (BMI). This degenerative disease relates to various lumbar disorders. Lumbar facet joint osteoarthritis (LFJOA) is highly prevalent, but relationship between this disease and SIJ degeneration remains poorly evaluated.

Objectives: This study aimed to investigate the relation between LFJOA and SIJ degeneration. We hypothesized that LFJOA patients might suffer more serious SIJ degeneration, thus multiple linear regression was employed to compare the effect of LFJOA and demographic characteristics on degeneration of SIJ.

Methods: We reviewed pelvic and lumbar computed tomography (CT) examinations of LFJOA patient with low back pain (LBP) through a picture archiving and communication system. The controls were age, gender and BMI-matched individuals who were free of LFJOA and LBP, and underwent pelvic and whole abdomen CT scans due to the non-musculoskeletal symptoms. Severity of SIJ degeneration was scored using a quantitative method which has been descripted by Bäcklund et al [1]. LFJOA was graded using a method which has been mentioned by Weishaupt et al [2]. Briefly, this method concerns facet joint space, osteophytes, hypertrophy of the articular processes, and subarticular bone erosions, which ranges from 0 to 3 for a joint. If there is a discrepancy between 2 joints in the same level, the greater one was used. LFJOA was defined at least one level $\geq 2$ from L1-2 to L5-S1. Scores of SIJ degeneration were compared between LFJOA patients and the controls. Correlation analysis between SIJ degeneration score and number of LFJOA levels, number of LFJOA joints, sum of LFJOA grades were performed. Stepwise multiple linear regression model was used to find the most important contributor of SIJ degeneration among LFJOA, gender, age and BMI.

Results: (1) CT examinations of 992 LFJOA patients and 399 controls were reviewed. (2) Score of SIJ degeneration in LFJOA patients were higher than that of the controls $(8.85 \pm 2.94$ vs. $4.31 \pm 2.52, P<0.05)$. (3) SIJ degeneration score positively correlated with number of LFJOA levels $(r=0.11, P<0.05)$, number of LFJOA joints $(r=0.09, P<0.05)$ and sum of grades $(r=0.10, P<0.05)$. (4) Results of multiple linear regression were shown in Table 1. LFJOA had the greatest standardized coefficient in the regression model.

Conclusion: LFJOA patients suffers more significant SIJ degeneration, and more severe LFJOA leads to more serious SIJ degeneration. Influence of LFJOA on SIJ degeneration is stronger than demographic characteristics.

\section{REFERENCES}

[1] Bäcklund J, Clewett Dahl E, Skorpil M. Is CT indicated in diagnosing sacroiliac joint degeneration? Clin Radiol 2017;72(8):693.e9-693.e13.

[2] Weishaupt D, Zanetti M, Boos N, et al. MR imaging and CT in osteoarthritis of the lumbar facet joints. Skeletal Radiol 1999; 28: 215-219.

Abstract THU0432 - Table 1. Stepwise multiple linear regression model for sacroiliac joints degeneration score

\begin{tabular}{|c|c|c|c|c|c|c|c|}
\hline \multirow[t]{2}{*}{$\begin{array}{l}\text { Independent } \\
\text { variables }\end{array}$} & \multicolumn{2}{|c|}{$\begin{array}{c}\text { Unstandardized } \\
\text { coefficient }\end{array}$} & \multirow[t]{2}{*}{$\begin{array}{l}\text { Standardized } \\
\text { coefficient }\end{array}$} & \multirow[t]{2}{*}{$P$ value } & \multicolumn{2}{|c|}{$\begin{array}{c}95 \% \text { confidence } \\
\text { interval for B }\end{array}$} & \multirow{2}{*}{$\begin{array}{c}\text { Variance } \\
\text { inflation } \\
\text { factor }\end{array}$} \\
\hline & $\bar{B}$ & SE & & & $\begin{array}{l}\text { Lower } \\
\text { bound }\end{array}$ & $\begin{array}{l}\text { Upper } \\
\text { bound }\end{array}$ & \\
\hline LFJOA & -4.49 & 0.12 & -0.58 & $<0.001$ & -4.73 & -4.25 & 1.00 \\
\hline Age & 0.124 & 0.00 & 0.55 & $<0.001$ & 0.12 & 0.13 & 1.01 \\
\hline BMI & 0.05 & 0.01 & 0.06 & $<0.001$ & 0.02 & 0.07 & 1.00 \\
\hline Gender & 0.30 & 0.11 & 0.04 & 0.009 & 0.08 & 0.53 & 1.01 \\
\hline
\end{tabular}

SE standard error, LFJOA lumbar facet joint osteoarthritis, $B M /$ body mass index $R^{2}=0.65$, adjusted $R^{2}=0.65$

Acknowledgement: None.

Disclosure of Interests: None declared

DOI: 10.1136/annrheumdis-2019-eular.2831

\section{THU0433 THE BURDEN OF OSTEOARTHRITIS PAIN FROM THE} PATIENT'S PERSPECTIVE IN EUROPE

James Jackson ${ }^{1}$, Wenhui Wen², Pavlina Hubanova ${ }^{1}$, Nathan Williams ${ }^{1}$, Jennifer Mellor ${ }^{1}$, Ravi lyer ${ }^{3} .{ }^{1}$ Adelphi Real World, Cheshire, United Kingdom; ${ }^{2}$ Regeneron Pharmaceuticals, Inc., Tarrytown, United States of America; ${ }^{3}$ Teva Pharmaceutical Industries, Frazer, United States of America

Background: Pain, the primary symptom of osteoarthritis (OA), affects multiple aspects of a patient's life.

Objectives: To evaluate the burden of $O A$ pain from the patient's perspective in 5 European countries (France, Germany, Italy, Spain, the United Kingdom; EU5). 